\title{
Factors Influencing the Purchase of Agro-Chemicals: from the Perspective of Sri Lankan Farmers
}

\author{
Mubarak kaldeen
}

\begin{abstract}
This study investigates the buying behavior of farmers towards agrochemical products which is considered as highly important for a healthy food concept. The key objective of the study is to investigate the key factors that influence and determine the buying behavior of farmers towards agro-chemicals. Questionnaire survey was conducted from 292 farmers selected by a convenient sampling in the district of Ampara, Sri Lanka. The multiple linear regression was used to achieve the objective of the study. The present study found that attitude, perceived availability, perceived price and product knowledge, word-of-mouth communication were significantly affecting the buying behavior of farmers towards agro-chemicals. Hence, the agrochemical marketers and dealers should formulate strategies to influence the buying behaviour of the farmers through effective marketing communications and made availabilities of agrochemical products in the market. This scenario would lead the agro-chemical consumers to avoid any irresponsible buying behaviors. This research is an opportunity and an eye-opener for marketers to increase their contribution towards agrochemical business and fulfill the demand for agrochemicals without any harm to the society and the environment.
\end{abstract}

Keywords :Buying behavior, Agro-Chemical, Attitude, Perception, Sri Lanka.

\section{INTRODUCTION}

The agricultural sector contributed about $7 \%$ of the gross domestic product in 2018 in Sri Lanka [1]. Agribusinesses play an important role in the development of a country's agricultural sector as suppliers of farming requisites such as fertilizer, agrochemicals, and feeds. The agrochemical industry in Sri Lanka falls in different categories such as insecticide, fungicides, and weedicides. Agrochemicals continue to be a significant and highly usable component in today's agriculture. The agrochemicals market is growing as the global economy recovers also becoming more prevalent in terms of a phenomenon in Sri Lanka. Agro-chemical business is a highly competitive one due to a large number of agrochemical companies in Sri Lanka and they are distributing more than hundreds of agrochemicals under different trade names. Over the years agro-chemicals have basically sold itself, but during the last decade, the market has become more competitive amongst local chemical producers as well as imported chemical products. According to the Department of Agriculture, Ampara, based on available

secondary data, the total sales of agrochemicals in 2016 was Rs. 7,621.4 million (Insecticides - 2,046 m, Fungicides -

Revised Version Manuscript Received on 16 September, 2019. * Correspondence Author

Mubarak kaldeen, Department of Marketing Management, Faculty of Management and Commerce, South Eastern University of Sri Lanka. Oluvil, \# 32360, Sri Lanka.kmmubarak@ seu.ac.lk
$1,016 \mathrm{~m}$ and Weedicides - 4,560 m). Most of the agro-chemicals are not manufactured in Sri Lanka and are either imported in bulk for re-packing or brought in as concentrates (technical grade material) for formulation locally prior to marketing whilst agro-chemical trade is solely handled by the private sector. The Registrar of Pesticides is the licensing authority revealed that about 37 agrochemical importers have registered under the Registrar of Pesticides.

Consumer behavior research enables better understanding and forecasting not only of the subject of purchases but also of purchasing motives and purchasing frequency [2]. One of the present fundamental presumptions for consumer behavior research is the fact, that people often buy products not because of their main function but for their subjectively perceived value. Thus, today's role of the product exceeds its service limits [3]. Even more often consumers do not rate products according to their cores, which means the main utility provided but above all according to the so-called real product, which means the particular products' qualities and the extended product, which represents the set of intangible factors bringing the demanded perceived advantage to the consumer. Thus, understanding the consumer purchase process is critical to a marketer so as to design the marketing activities effectively.

Therefore, this research intended to study in-depth on this area based on Sri Lanka agrochemical business to help local retailers understand about the impact of internal and external factors on purchasing behavior of farmers in Sri Lanka. Hence this study investigates the influence of key determinants of buying behavior of farmers towards agrochemicals in Ampara District, Sri Lanka.

\section{REVIEW OF LITERATURE}

Attitudes towards behaviour play an important role in explaining human behaviour. Stronger attitudes towards behaviour lead to the stronger intention to perform this behaviour. People hold some beliefs about a particular object. Then each belief links behaviour to some outcome. Hence, people favourbehaviours which they believe have desirable consequences and hold unfavourable attitudes toward behaviours which they linked with undesirable consequences [4]. Attitudes towards buying products have been studied in a number of studies. In the majority of cases the authors found a strong and positive relationship between attitudes and intention to buy [5].

Perceived availability of product studied by Vermeir, [6] and found that perceived availability has a highly significant and positive impact on sustainable consumption intention. investigated Ahamed, consumers' 
intention to buy products, discovered that the perceived availability of preferred products is one of the important determinants of consumers' intention to buy goods and services. Furthermore, Aziz, [4] concluded that the availability of a preferred product was one of the key deterrents of its purchase.

Perceived price is a significant driver of purchase intention and one of the main influencers of the intention to buy products. Ahamed, [7] discovered that there exists a strong association between a purchase of agrochemicals and an affordable price among consumers. Moreover, Aziz, [4] suggested that price is an important determinant of intention to goods and services.

Product knowledge has been identified as key determinant and consumers often need relevant product-related information for a purchase. As a presumption of intention to buy consumers need to be able to identify agro-chemicals first. According to Gracia [8], product knowledge is an important factor because it is the only instrument that consumers have in order to differentiate the attributes of agrochemical products and to form positive attitudes, and quality perceptions toward these products. Ahamed [7] proposed that knowledge about a particular product and service may affect buying decisions. Gracia [8] found a significant effect of product knowledge on consumer buying behavior.

Word of mouth communication is another important determinant explaining the intention to buy agro-chemical products. It is important individuals or groups approve or disapprove of performing a given behavior [4]. The logic behind this factor is that if consumers believe that people who are important to them think that agrochemicals are good, they will express more intention of buying agrochemical products [5]. A significant relationship between word of mouth communication and intention to buy agrochemicals has been found in several studies [5]. Influential external an internal factor identified through extracted literature summarized as conceptual framework illustrated below in Fig. 1.

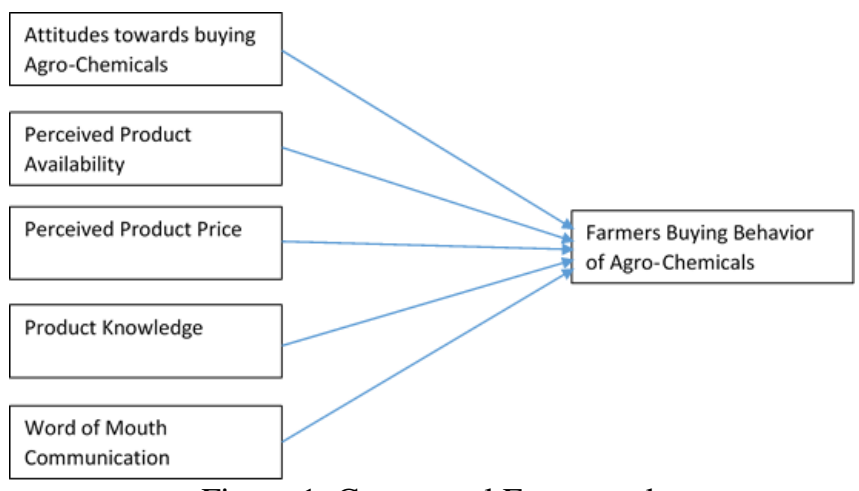

Figure 1: Conceptual Framework

\section{MeThodology}

The research method was quantitative and primary data collected from 300 respondents farming in Ampara District, Sri Lanka using a questionnaire survey. The questionnaire was developed by adapting the indicators of previous studies and piolet test was carried out to measure the reliability and validity of the instrument prior to proceed final data collection. Based on the non-probability sampling method, the convenient sampling technique was used to choose 300 respondents and questionnaires were self-administered by drop-off pick-up method. Respondents were requested to provide answers for the questions in the questionnaire administered by a researcher. The researcher read out the questions and filled the questionnaire with the given answer by the farmer 290 usable questionnaires were used for statistical analysis. Data analyzed using SPSS:21. Both independent variables (attitudes towards buying agrochemicals, perceived availability of the product, perceived price, product knowledge, and word of mouth communication) and dependent variable (buying behavior of farmers) were measured using a five-point Likert scale. Thus, data was collected by asking the respondents to place their degree of agreement on a scale provided in the questionnaire, which was expressed in terms of scores at the stage of coding (1 - Strongly Disagree, 2 - Disagree, 3 - Neutral, 4 - Agree and 5 - Strongly Agree)

\section{DATA ANALYSIS}

The Cronbach's Coefficient Alpha test is used to test the degree of the inter-item consistency of an instrument and how well it positively correlated to one another. Closer the Cronbach's alpha is to 1 , the higher the internal consistency reliability [9]. Convergent validity was tested among the factors by correlation analysis and stringent tests. Following multiple regression analysis was done using SPSS Statistics - 21.0 to examine the effect of independent variables (Attitude toward agrochemicals, perceived product availability, perceived price, product knowledge and word of mouth communication) and buying behavior of farmers with hypothesis developed from past literature. The hypotheses developed for this study are given below;

H1: Attitudes towards agrochemicals influence the farmer's buying behavior of agrochemicals.

$\mathrm{H} 2$ : Perceived availability of the preferred agro-chemicals influences farmers buying behavior of agrochemicals.

H3: Perceived price influences the farmers' buying behavior of agrochemicals.

H4: Product knowledge of consumers influences the farmers' buying behavior of agrochemicals.

H5:Word of mouth communications influence the farmer's buying behavior of agrochemicals.

$$
Y=\beta_{0}+\beta_{1} \mathrm{X}_{1}+\beta_{2} \mathrm{X}_{2}+\beta_{3} \mathrm{X}_{3}+\beta_{4} \mathrm{X}_{4}+\beta_{5} \mathrm{X}_{5}+u
$$

(Where, $\mathrm{Y}=$ Buying behavior of Farmers; $\mathrm{X}_{1}=$ Attitudes; $\mathrm{X}_{2}$ $=$ Perceived availability of product; $\mathrm{X}_{3}=$ Perceived price; $\mathrm{X}_{4}$ $=$ Product knowledge $\mathrm{X}_{5}=$ Word of mouth communication)

\section{RESULTS AND DISCUSSION}

All respondents of the farmers were males, it clearly shows that mainly men are involved in agriculture in the Ampara district. More than half of the farmer's average age was in between 51-60 years whereas only 9\% of the farmers between 31-40 years age group. Which witnesses that the future of agriculture in the Ampara district requires more labor force to increase production unless the technology is improved. When it comes to experience in farming, where around $32 \%$ of the respondents had more than 20 years. Meantime around half of the sample had 15-20 years of farming experience. 
The standardised coefficient shows that the highest number in the beta is 0.292 for perceived availability of product, which is significant at the 0.000 level. This indicates that the Buying behavior of farmers at towards agro-chemicals is influenced by perceived availability of products. The coefficient of perceived availability of product is a determinant factor of Buying behavior of farmers, a one percent increase in perceived availability of product would rise to a 0.292 percent increase in Buying behavior of farmers. Conversely, Coefficient of product knowledge is another determinant factor of Buying behavior of farmers towards agro-chemicals which would give 0.286 percent increase in Buying behavior of farmers, a one percent increase in word of mouth communication would give 0.184 percent increase in Buying behavior of farmers towards agro-chemicals. At the same time coefficient of Perceived price in the key determinants of buying behavior of farmers towards agro-chemicals indicates that one percent increases would lead to 0.075 percent increase Buying behavior of farmers and Attitude would rise by .067 percent. All predictors are significant to the model at 0.05 level.

The correlation analysis results indicated that all the independent variables, Attitudes, Perceived availability of product, Perceived price, Product knowledge, and Word of mouth communication have positively correlated with Buying behavior of farmers $(\mathrm{p}<0.05)$ at $1 \%$ significant level. Association of Attitude, Perceived price and Product knowledge with Buying behavior of farmers towards agro-chemicals is moderate level while the association between perceived availability of product, word of mouth communication with buying behavior of farmers towards agro-chemicals is strong positive. According to the analysis, $r$ values between attitude (0.592), perceived availability of product $(0.602)$, perceived price $(0.422)$, product knowledge (0.406) and word of mouth communication (0.604) with buying behavior of farmers towards agro-chemicals. Thus, buying behavior of farmers towards agrochemicals is positively associated with all five predictors.

The overall model explains the fit for the research. $\mathrm{R}^{2}$ in the table given below shows this aspect. The coefficient $R^{2}$ is an extension to multiple regression of the coefficient of determination $r^{2}$ in a simple linear equation. According to the analysis the $\mathrm{R}^{2}$ is 0.540 (54 percent), hence, the regression equation apparently has a perfect fit with the data. It can be predicted that $54 \%$ of the variance ( $R$-square) in dependent variable has been significantly explained by the five independent variables (Attitudes, Perceived availability of product, Perceived price, Product knowledge and Word of mouth communication). Here, $\mathrm{p}=0.000<0.05$ and ANOVA table shows that the $F$ value of 44.631 is significant at the 0.000 level. So the model is significant and model exists.

When the individual variables are focused, at first, the Attitudes is considered; $\mathrm{p}=0.010<0.05$, hence, highly significant and explain a much about the dependent variable. Perceived availability of product values; $p=0.044<0.05$, highly significant to the model. Perceived price values; $\mathrm{p}=$ $0.047<0.05$, significant to the model. Product knowledge values; $p=0.000<0.05$ highly significant to model. Finally, Word of mouth communication; $\mathrm{p}=0.002<0.05$, which was also significant to the model.

The multiple regression model in the methodology part was estimated. The results are shown in Table 1 indicated that all the variables significantly affected the buying behavior of the farmer towards agrochemical.
Table 1: Multiple regression analysis results

\begin{tabular}{|c|c|}
\hline Variable & Coefficient \\
\hline Attitude & $0.67(0.22)^{* * *}$ \\
\hline $\begin{array}{l}\text { Perceived availability of } \\
\text { product }\end{array}$ & $0.29(0.63)^{* * *}$ \\
\hline Perceived price & $0.08(0.04)^{* * *}$ \\
\hline Product knowledge & $0.29(0.05) * * *$ \\
\hline $\begin{array}{l}\text { Word of mouth } \\
\text { communication }\end{array}$ & $0.18(0.61)^{* * *}$ \\
\hline
\end{tabular}

Since the independent variables significantly $(\mathrm{p}<0.05)$ had positive impact on agro-chemical buying behavior of farmer at 5\% significant level, the all the hypothesis of farmer attitude towards agro-chemicals, farmer perceived availability of products, farmer perceived price, farmer product knowledge and farmer's word of mouth communication were accepted at 5\% significant level. Furthermore, $54 \%$ of the variance (R-square) in dependent variable has been significantly explained by the five independent variables (Attitudes, Perceived availability of the product, Perceived price, Product knowledge and Word of mouth communication). Hence the following Model fit regression equation is derived.

\section{$Y=0.755+0.067 X_{1}+0.29 X_{2}+0.08 X_{3}+0.29 X_{4}+0.18 X_{5}$}

Attitudes towards behavior play an important role in explaining human behavior. Stronger attitudes towards behavior the stronger intention to perform this behavior Consumers hold rather positive attitudes towards buying agrochemicals. This finding is consistent with previous studies [5]; [6]. Since the relationship between attitudes towards buying and buying behavior of farmers has been found strong and positive, it suggests that stronger attitudes towards buying it may lead to stronger behavior towards buying agrochemicals. Further, this study results indicated that consumers ready to buy the agro-chemicals upon their availability. This finding is consistent with previous studies [5]. Since the relationship between the perceived availability of products and buying behavior of farmers found strong and positive, it suggests that if the agro-chemicals are available, it may lead to stronger behavior towards buying agrochemicals.

Perceived price influences the farmers' buying behavior of agro-chemicals. Former research [7], reported this factor as influencing the buying behavior of related commodities. Since the perceived price is one of the important factors in consumer behavior studies this study evidence for the effect of consumer behavior towards agrochemical in the market. The relationship between product knowledge and the actual purchase is positive suggesting that higher knowledge about agrochemicals contributes to the higher actual purchase. Based on the findings of this study the majority of consumers are able to recognize agro-chemicals. However, consumers expressed that they do not have good knowledge about the impact of agrochemicals on their final product, and have difficulty to know the safe side of the final product. However, 
the findings of this study did not find any significant effect of product knowledge on the buying behavior of farmers towards agro-chemicals. Most of the farmers rely on the communication of other farmers, members of farmer associations or opinion of experts like Agrarian officers to make their choice of brands, it is because those farmers were very reluctant to buy agrochemicals which are new to them and which has no positive endorsement from others.

\section{CONCLUSIONS AND RECOMMENDATIONS}

The purpose of this study was to examine the influence of the determinants of the buying behavior of farmers towards agrochemicals. In conclusion, attitude towards agro-chemicals, perceived availability of products, perceived price, product knowledge and word of mouth communication have a significant impact on farmers buying behavior towards agro-chemicals in Ampara district. Among the above word of mouth, communication relationships should be given high consideration as it showed a higher correlation with buying behavior of farmers towards agro-chemicals, second is the perceived availability of products comes in the rank. However, there cannot be one particular determinant that works best in every circumstance. The marketers of agro-chemicals have to find out the best mix of determinants that increases the intention to spend more time and money, purchase more items and repeat purchase intention. Thus, the agrochemical marketers and sellers make enough availabilities of agrochemical products in the market resulting that, the irresponsible buying behaviors of farmers towards agrochemicals would be used as opportunities by agrochemicals marketers for increasing their market share in the agrochemical industry in Sri Lanka. Therefore, the new plan of authority should implement some controlling mechanism to fulfill the demand for agrochemicals without any harm to the society and the environment.

The cross-sectional nature of this study limits the understanding of the farmers' behavioral and attitudinal changes over time. Further, the farmers' responses are not comparatively studied based on varied chemical types such as chemical powder and liquid chemical and demographic profiles. The cross-sectional nature of this study limits the understanding of the farmers' behavioral and attitudinal changes over time. Further, the farmers' responses are not comparatively studied based on varied chemical types such as chemical powder and liquid chemical and demographic profiles. This study brought out knowledge about the present status and framework of the agrochemical business environment in Sri Lanka. The findings of this study raised awareness of the agrochemical (toxic, poison) applications that can be adopted wherever possible in the future.

\section{REFERENCES}

1. Annual Report, Central Bank of Sri Lanka, 2018, available at https://www.cbsl.gov.lk , publications, economic-and-financial-reports

2. L. G. Schiffman and L.L. Kanuk, Consumer behavior. London, Prentice. Hall. 2010.

3. V. Sivakumar, and S. Kaliyamoorthy, Factors influencing the purchase of agricultural tractors: An empirical study. Journal of Business and Management. 2014;16(1):42-6.

4. N. A. B. A. Aziz, N. N. B. A. Aziz, and Y. B. W. Aris, Factors influencing the paddy farmers' intention to participate in agriculture Takaful. Procedia Economics and Finance. 2014; 31, pp.237-242.

5. M. Chen, Attitude toward Organic Food among Taiwanese as related to health consciousness, environmental attitudes, and the mediating effects of a healthy lifestyle. British Food Journal. 2009;111(2), pp.165-178.

6. I. Vermeir, and W. Verbeke, Sustainable food consumption among young adults in Belgium: Theory of planned behaviour and the role of confidence and values. Ecological Economics. 2007;64(3), pp. 542-553.

7. S.N. Ahmad, and N. Juhdi, Organic food: A study on demographic characteristics and factors influencing purchase intentions among consumers in Klang Valley, Malaysia. International journal of business and management. 2010 Feb 1;5(2):105.

8. A. GraciaRoyo, T. de-Magistris, and J. Barreiro Hurlé, Why do we buy organic? Integrating knowledge, attitudes and concerns in a simultaneous equation model for Spanish consumers. 119th EAAE Seminar 'Sustainability in the Food Sector: 2010.

9. U. Sekaran, and R. Bougie, Research methods for business: A skill building approach. John Wiley \& Sons; 2016 Jun 27. 